REVESCO. Revista de Estudios Cooperativos

ISSN: $1885-8031$

http://dx.doi.org/10.5209/REVE.58136

\title{
Aplicación, desarrollo y reforma de la Ley 5/2011 de Economía Social. ¿Un derecho debilitado?
}

\author{
José María Pérez de Uralde ${ }^{1}$
}

Recibido: 1 de febrero de 2017 / Aceptado: 19 de octubre de 2017

Resumen. La entrada en vigor de la Ley 5/2011, de Economía Social, debería haber contribuido a facilitar cierta elaboración científico-jurídica entorno a un posible Derecho de la Economía Social. Sin embargo, la parquedad de su texto, su falta de aplicación, la ausencia absoluta de desarrollo reglamentario y una reforma errónea, impiden tal pretensión. La inconsistente construcción técnica de esta Ley, su inaplicación radical, la falta de desarrollo reglamentario mínimo y una muy discutible reforma la configuran en términos de ineficiencia, aproximándola a un tipo de producción jurídica carente de efectos prácticos. La confusión de rangos normativos, el proceloso y confuso proceso deslegalizador al que es sometida, la indeterminación material y de fuentes, la inseguridad jurídica que todo ello propicia y, sobre todo, su flagrante y nocivo incumplimiento, la sitúan al borde mismo del llamado "Derecho blando" y/o del "Derecho imperfecto", donde desaparecen las características más determinantes que otorga la llamada "fuerza de Ley". La Economía Social merece otro trato legal que permita consolidar puntos de partida que alienten la construcción de un sistemático Derecho de la Economía Social, basado en la homologación de conceptos referenciales y permita culminar una construcción holística realmente necesaria.

Palabras clave: Preámbulo; Reglamento; Deslegalización; Jerarquía normativa; Seguridad jurídica; Incumplimiento.

Claves Econlit: K290; K300; K390; K420; L380.

\section{[en] Application, development and reform of Law 5/2011 of Social Economy. A weak right?}

\begin{abstract}
The entry into force of Law 5/2011, of Social Economy, should have contributed to facilitate some scientific-legal elaboration around a possible Law of the Social Economy. However, the paucity of its text, its lack of application, the absolute absence of regulatory development and an erroneous reform, preclude such a claim. The inconsistent technical construction of this Law, its radical inapplicability, the lack of minimum regulatory development and a very debatable reform shape it in terms of inefficiency, approaching a type of legal production lacking practical effects. The confusion of normative ranges, the protracted and confused process of delegitimation to which it is subjected, the material and indeterminacy of sources, the legal insecurity that all this propitiates and, above all, its flagrant and harmful non-fulfillment, place it at the very edge of the so-called " Soft law "and / or" imperfect law ", where the most determining characteristics of the so-called" force of law "disappear. The Social Economy deserves another legal treatment that allows to consolidate starting
\end{abstract}

$1 \quad$ Abogado

Dirección de correo electrónico: puralde@telefonica.net 
points that encourage the construction of a systematic Social Economy Law, based on the homologation of referential concepts and allows to culminate a holistic construction really necessary. Keywords: Preamble; Regulation; Legalization; Legal hierarchy; Legal certainty; Non-compliance.

Sumario. 1. Introducción. 2. Aplicación de la Ley 5/2011 de Economía Social a partir de 2015. 3. Desarrollo reglamentario de la Ley 5/2011 de Economía Social. 4. Reforma de la Ley 5/2011 de Economía Social. 5. La regulación legal de la Economía Social. Entre la Ley formal y el "derecho blando". 6. Conclusiones. 7. Referencias bibliográficas.

Cómo citar: Pérez de Uralde, J.M. (2017) Aplicación, desarrollo y reforma de la Ley 5/2011 de Economía Social. ¿Un derecho debilitado?. REVESCO. Revista de Estudios Cooperativos, $\mathrm{N}^{\mathrm{o}} 125$, pp. 134-158. DOI: 10.5209/REVE.58136.

\section{Introducción}

La Economía Social (ES), entendida como el conjunto de entidades y empresas que realizando actividad económica se constituyen con base en los principios específicos institucionalizados legalmente según prescribe el artículo 4 de la Ley 5/2011 de Economía Social (en adelante LES) ${ }^{2}$, viene precisando, especialmente desde la aprobación de esta norma, de un suficiente tratamiento unitario que asegure una visión teórica de conjunto. Hasta la entrada en vigor de la LES las normas jurídicas afectantes a las entidades de ES se han caracterizado por carecer de puntos de referencia directos que las vinculen a un concepto holístico inclusivo y definitorio. Sin embargo, es una realidad incuestionable que la producción científica sobre la materia es amplia, rigurosa e integradora desde hace mucho tiempo. La aparición de una Ley que tiene por objeto declarado en su artículo 1 el establecimiento de "un marco jurídico común para el conjunto de entidades que integran la economía social... ” podía permitir articular una elaboración sistemática que diera coherencia al conjunto de realidades jurídicas existentes. Partiendo del impulso básico de la Constitución de 1978 (artículo 129.2) se ha abogado por favorecer una función heurística que permita incluso diseñar un sistema jurídico específico (Cano López, 2002; Sánchez Pachón, 2008)) ya que como concepto identificador de esta realidad no ha tenido reflejo hasta ahora en la legislación española (Paz Canalejo, 2012). Sistema que ha de elaborarse y completarse a partir del análisis e interpretación de la propia legislación de ES vigente y que permita superar la situación inconexa que caracteriza a las normas que regulan las distintas figuras de la ES (Cano López, 2007; Paniagua, M y Jiménez, J, 2014).

Es un hecho que la ES se forma a partir de heterogéneas figuras jurídicas que, sin embargo, coinciden en una serie de principios constitutivos que la propia LES especifica (Fajardo García, 2012). La existencia de una Ley que dota de "marco jurídico" al sector fue, sin duda, una buena noticia también para los partidarios de una teoría jurídica de la ES. La falta de aplicación efectiva de esta norma, la ausencia de desarrollo reglamentario y una malograda reforma hacen, lamentablemente, que no sea de demasiada utilidad a tales fines. Por otro lado, suele ser frecuente encontrar en la doctrina referencias muy críticas con respecto a

2 BOE número 76, de 30 de marzo de 2011. 
las específicas regulaciones sectoriales. Por ejemplo, en cooperativas Paz Canalejo (2007), Paniagua y Jiménez (2014) o con respecto a las empresas de inserción Cano López (2011). Ello podría consolidar también un criterio que ponga en duda que se esté fomentando a la ES mediante una legislación adecuada.

La utilidad de una Ley que propicie un marco jurídico común debería reflejar criterios de homogeneidad y cierta homologación general que permita acabar con tales defectos. La LES no está sirviendo para mucho en ese sentido. Al contrario más bien, ya que puede estar generando riesgos jurídicos en cuanto a su aplicación. En palabras de Ollero Tasser (2003) "Las normas no nos acaban de transmitir su mensaje hasta que cobran existencia entrando en correspondencia con hechos concretos". El mensaje de la LES está por conocerse.

El presente trabajo pretende demostrar, al menos indiciariamente y sobre la base de la trayectoria seguida efectivamente desde su entrada en vigor, que la norma jurídica que de manera expresa regula la ES española adolece, fundamentalmente, de una mínima efectividad. Asignar a esta Ley 5/2011 el concepto de "fuerza de Ley" resulta muy difícil y, por ello, podemos calificarla de Ley "débil" o, en terminología doctrinal, como parte del "derecho blando" (soft law), y, también, de ese grupo de normas que conforman el denominado, por carecer de consecuencias o efectos su inaplicación, "derecho imperfecto".

Para ello, se analiza la Ley 5/2011 a partir de tres parámetros específicos: su aplicación real y efectiva; su desarrollo reglamentario y su reciente reforma. Tres aspectos que permiten contrastar la efectividad de una norma que pretende ser el "marco jurídico" de un sector, la ES, tan importante en el ámbito económico como esencial en el desarrollo social.

\section{Aplicación de la Ley 5/2011 de Economía Social a partir de 2015}

La LES ha permanecido, tras cinco años de vigencia, sin ser apenas aplicada ni desarrollada (Pérez De Uralde, 2014). No pueden considerarse, en puridad, como aplicaciones de la Ley las referidas a materias ajenas al objeto de la norma y que fueron incorporadas al texto a través de la muy nociva técnica legislativa consistente en incardinar "normas intrusas" aprovechando la oportunidad del rango legal (Paz Canalejo, 2012; Pérez De Uralde, 2012) ${ }^{3}$. Si valdría considerar aplicación lo dispuesto en la Disposición transitoria segunda en relación a las cooperativas de vivienda en cuanto materia propia de la ES, consistente en una medida anticrisis que favorece el alquiler y venta a terceros de viviendas en régimen cooperativo.

Puede hablarse, por fin, de aplicación de la LES, con notable retraso según las previsiones temporales de la propia Ley (más de 4 años), al ejecutarse algunas de las medidas contempladas en su Disposición adicional séptima ${ }^{4}$. El programa de

3 En concreto: la disposición adicional sexta sobre "Ejercicio de actividades sanitarias por titulados universitarios de Licenciado en Psicología o Graduado en el ámbito de la Psicología" y la Disposición final tercera sobre "Modificación del texto refundido de la Ley General de la Seguridad Social, aprobado por el Real Decreto Legislativo 1/1994, de 20 de junio."

4 Disposición adicional séptima de la Ley 5/2011: "Programa de impulso de las entidades de economía social. 
impulso previsto en dicha Disposición adicional se ha pretendido concretar por parte del Ministerio de Empleo y Seguridad Social a través del documento titulado "Programa de Fomento e Impulso de la Economía Social 2015-2016", de fecha 20 de julio de $2015^{5}$. Lo que nos interesa destacar de este Programa es que, entre otras medidas, se establecen dos de las previstas en la antecitada disposición adicional séptima. En concreto, el Eje 2 del Programa lleva por enunciado "Revisión y actualización del marco jurídico con el objeto de eliminar las limitaciones a las entidades de la economía social, simplificar trámites y armonizar regímenes". Sin embargo, ninguna de las medidas incorporadas a este Eje parece responder al mandato de la primera medida señalada por la LES sobre revisión de la normativa para eliminar las limitaciones de las entidades de la ES de forma que puedan operar en cualquier actividad económica sin trabas legales injustificadas. ${ }^{6}$

Sí se ha desarrollado la medida segunda prevista en la Disposición adicional séptima relativa a la actualización y revisión de la Ley 4/1997, de 24 de marzo, de Sociedades Laborales, mediante la aprobación de la Ley 44/2015, de 14 de octubre de Sociedades Laborales y Participadas. ${ }^{7}$ No es objeto del presente trabajo el estudio de esta Ley 44/2015; sin embargo no es fácil evitar algún pronunciamiento crítico con respecto a la calidad técnica de esta norma ya que consideramos que puede incumbir al propósito de este trabajo (García Ruíz, 2016). Coincidimos de plano con Olavarría Iglesia (2015) en criticar con rotundidad la regulación que se ha efectuado de las llamadas "sociedades participadas". Señala este autor que "la extrema ambigüedad e indeterminación de la regulación de las sociedades participadas en la nueva Ley puede suponer un serio peligro de dilución de las sociedades laborales en una categoría-las sociedades participadas- que, dados los términos en que viene reconocida, podría estar el margen de la Economía Social, al caber en dicha categoría sociedades que poco o muy poco tienen que ver con las

\footnotetext{
El Gobierno aprobará en el plazo de seis meses desde la entrada en vigor de esta Ley, un programa de impulso de las entidades de economía social, con especial atención a las de singular arraigo en su entorno y a las que generen empleo en los sectores más desfavorecidos. Este programa entre otras reflejará las siguientes medidas:

1. ${ }^{\circ}$ Previa consulta a las entidades representativas de la economía social, del Consejo para el Fomento de la Economía Social y de las Comunidades Autónomas, revisará la normativa necesaria para eliminar las limitaciones de las entidades de la economía social, de forma que estas puedan operar en cualquier actividad económica sin trabas injustificadas.

$2 .^{\circ}$ Previa consulta a las entidades representativas de la economía social, del Consejo para el Fomento de la Economía Social y de las Comunidades Autónomas, remitirá a las Cortes un proyecto de ley que actualice y revise la Ley 4/1997, de 24 de marzo, de Sociedades Laborales.

3. ${ }^{\circ}$ Previa consulta con las entidades que realizan acción social revisará la normativa de desarrollo de la Ley 38/2003, de 17 de noviembre, General de Subvenciones, que les es de aplicación, con el objeto de simplificar los procedimientos regulados en la misma."

5 La Dirección General del Trabajo Autónomo, de la Economía Social y la Responsabilidad Social de las Empresas, dependiente de la Secretaría de Estado de Empleo del Ministerio de Empleo y Seguridad Social del Gobierno de España dio a conocer con fecha de 20 de julio de 2015 el Programa de Fomento e Impulso de la Economía Social 2015-2016. Estructurado en cuatro objetivos y siete ejes incluye 32 medidas de diferente signo y alcance. Web del Ministerio.

6 Las medidas concretas incluidas en el Eje 2 del Programa son: .- Desarrollo de la Ley de Economía Social; .Modernización de la normativa de las Sociedades Laborales;.- Implantación del "Documento Único Electrónico" en el ámbito de la economía social y .- elaboración del "Catálogo de entidades de la Economía Social".

7 BOE número 247, de 15 de octubre de 2015. Aunque ciertamente los trabajos relativos al proyecto de Ley estaban prácticamente ultimados antes de la publicación del Programa de Fomento e Impulso de julio de 2015.
} 
características propias de aquellas". Estamos totalmente de acuerdo. La definición que el artículo 19 de esta Ley hace de las "sociedades participadas" incluye la determinación de que serán consideradas como tales "las sociedades anónimas o de responsabilidad limitada que no alcancen los requisitos establecidos en el capítulo I". Este capítulo regula el régimen jurídico de las sociedades laborales, por lo que puede llegar a pensarse que éstas no son "sociedades participadas" 8 . A la confusión contribuye el Preámbulo de la Ley ya que incluye a las sociedades laborales dentro de las "sociedades participadas". Como hemos de ver más adelante, nos encontramos ante una forma de legislar para la ES que navega entre lo difuso y las declaraciones tan categóricas como inefectivas.

No se ha abordado la medida tercera incluida en la disposición adicional relativa a la revisión de la Ley General de Subvenciones. Además, el texto mismo del Programa de Fomento e Impulso nos sirve de guía sobre otros aspectos de la LES que están pendientes de ejecutar, en concreto, y dentro del ya citado Eje 2, el "Desarrollo de la Ley de Economía Social", con la reforma del Consejo para el Fomento de la Economía Social ${ }^{9}$ y la elaboración del "Catálogo de entidades de la Economía Social" $" 10$. Dos importantes mandatos legales que siguen sin afrontarse.

En relación a las dos medidas adoptadas hasta la fecha en aplicación de la LES, y dejando el tema del retraso sufrido, no podemos eludir un comentario sobre un insistente y relevante defecto de forma que se viene consolidando en la aplicación tanto de las medidas derivadas de la Disposición adicional séptima como en cualquiera otra que se adopta en relación con la materia de la ES. Nos referimos al incumplimiento sistemático del artículo de la Ley que regula el Consejo para el Fomento de la Economía Social relativo a su intervención con carácter previo a la formalización de cualquiera de las medidas (más adelante nos detendremos en ello). En ese sentido, el incumplimiento de la LES también se muestra con evidencia con respecto al apartado 4 de su artículo 8 en lo que se refiere a la colaboración con las CCAA ${ }^{11}$.

\section{Desarrollo reglamentario de la Ley 5/2011 de Economía Social}

La Ley sigue sin desarrollo reglamentario alguno a pesar de la habilitación general (Disposición final segunda) y del mandato específico sobre la reforma y régimen transitorio del Consejo para el Fomento de la Economía Social del actual artículo 13 (antes artículo 9). Esta realidad puede generar dos tipos de valoraciones, ambas poco favorables. Por un lado, una de carácter general centrada en la deficiencia técnica de la Ley como una causa directa que dificulta su desarrollo reglamentario.

8 En ese sentido, puede situarse la posición de Calvo Ortega y Calvo Vergez (2016) cuando, refiriéndose al artículo 129.2 de la Constitución, concluyen que "En definitiva, cooperativas y sociedades laborales son entidades de economía social que no están pensadas como mecanismos jurídicos de participación y sí como empresas propiedad de los mismos trabajadores."

9 Actual artículo 13 de la LES tras su reforma (antiguo artículo 9)

10 Artículo 6 de la LES.

11 Textualmente: “4. En el desarrollo de las actividades de fomento de la economía social se respetarán las competencias de las Comunidades Autónomas. Desde la Administración General del Estado se impulsarán los mecanismos de cooperación y colaboración necesarios con las Administraciones Autonómicas para el desarrollo de las actividades de fomento de la economía social." 
Otra, sobre la apariencia de que el objeto de la Ley sea considerado poco relevante por parte de quien está llamado esencialmente a aplicarla: las administraciones públicas, referidas éstas en términos generales y a todos los niveles, tanto desde el punto de vista jerárquico como competencial, aunque la aplicación directa de la LES se concentra en la Administración central y las CCAA. Recalcando que la responsabilidad más contundente recae en el Gobierno central dado el carácter estatal de la LES (artículo $97 \mathrm{CE}$ ).

En cuanto a la primera consecuencia, la dogmática jurídica viene señalando, desde hace décadas, posturas muy críticas con respecto a la progresiva pérdida de calidad en la elaboración de las leyes, acosadas por actuaciones legislativas que muchas veces son deudoras de una posición de real sumisión al "verdadero poder legislativo" (Pendas García. 1989. García de Enterría, 1999). Sin embargo, no creemos que en este caso se de esta patología de sumisión habida cuenta, por un lado, el grado de consenso que suscitó en la totalidad de los grupos parlamentarios, no siendo, por tanto, fruto de imposición del grupo mayoritario que apoyaba al gobierno en el momento de aprobarse la Ley. Consenso que ahora parece flaquear precisamente en el ámbito autonómico ${ }^{12}$.

Además, como veremos, es ésta una norma que con aquiescencia general dejó la puerta totalmente abierta a su desarrollo reglamentario por parte de la Administración. El dato cierto es que tal amplitud a favor del ejecutivo no ha sido utilizada de ningún modo tras cinco años de vigencia formal de la Ley. La Administración ha renunciado en este tiempo al ejercicio de la potestad reglamentaria y a la colaboración y cooperación con el resto de las administraciones para el desarrollo de la Ley.

La llamada "potestad reglamentaria" atribuida en exclusiva a la Administración Pública (García de Enterría-Fernández, 1995) consiste en la capacidad de dictar normas con rango inferior a la Ley a cargo del gobierno central y también de los gobiernos autonómicos. Es, en palabras de Santamaría Pastor

12 Es el caso de la aprobación de la Ley 6/2016, de 4 de mayo, de la economía social de Galicia (DOG núm. 93, de 18 de mayo de 2016; BOE núm. 147 de 18 de junio de 2016.) aprobada con el apoyo exclusivo del grupo popular y en contra del resto de grupos parlamentarios (Pleno del 26 de abril de 2016; BOPG núm. 639, de 28 de abril de 2016).

Resulta también llamativa la posición del Parlamento Vasco en el Pleno celebrado el 5 de mayo de 2016 al tratarse varias proposiciones no de Ley sobre la creación del Consejo Vasco de la Economía Social o sobre la elaboración de un catálogo vasco de entidades de ES. Ambas propuestas fueron rechazadas sobre la base del incumplimiento que sobre tales materias viene asumiendo el gobierno central a pesar de los mandatos de la LES, y también, la falta de necesidad de adoptar tales medidas. En tal sentido, el incumplimiento de la LES está causando también radical desapego del resto de las administraciones hacia un texto legal caracterizado por su indolencia, contribuyendo aún más con ello a su ineficacia. El caso del Parlamento Vasco resulta especialmente claro al rechazar la posibilidad de crear el catálogo de entidades de ES a pesar de ser un mandato legal recogido en el artículo 6 de la LES que establece textualmente que "El Ministerio de Trabajo e Inmigración (hoy de Empleo y Seguridad Social), previo informe del Consejo para el Fomento de la Economía Social, y en coordinación con las Comunidades Autónomas, elaborará y mantendrá actualizado un catálogo de los diferentes tipos de entidades integrantes de la economía social, teniendo en cuenta los principios establecidos en la presente ley y de forma coordinada con los catálogos existentes en el ámbito autonómico. Los catálogos de entidades de economía social deberán ser públicos. La publicidad se hará efectiva por medios electrónicos." Una mayoría de parlamentarios vascos rechazó la propuesta de promover la creación del citado catálogo aludiendo no solo al hecho de que estaba pendiente el del gobierno central, sino también con el argumento de que en el caso vasco no es necesario hacerlo. (Pleno del 5/5/2016. Boletín Oficial del Parlamento Vasco de 13/5/2016. Transcripción del Pleno páginas 177 y ss. Web: www.legebiltzarra.eus). 
(2004), “...un ámbito literalmente inmenso : un gigantesco almacén en el que se deposita no menos del 98 por 100 de las disposiciones que integran el sistema normativo, en el que las normas presentan una variedad extraordinaria, poco menos que aberrante y, en que, sobre todo, los principios clásicos del Estado de Derecho poseen una eficacia ciertamente disminuida...". Se constituye, por tanto, en una capacidad sin duda muy atractiva ya que otorga un gran poder regulatorio directo y expansivo. Es cierto que es una potestad que depende de una Ley habilitante ya que, salvo algunas excepciones referidas al funcionamiento interno de la Administración, no hay reglamento sin Ley, pero la tendencia que se constata es que las habilitaciones son genéricas y sin límites. Para autores como Paz Canalejo (2012) en relación a la LES, y a pesar de tales peligros, la potestad reglamentaria pudiera haber sido una oportunidad para solventar los graves problemas que plantea su redacción. La consideración de la LES por parte de este autor como una Ley “...de carácter minimalista” sitúa su desarrollo reglamentario en un plano muy relevante. En ese sentido, la intervención preceptiva del Consejo para el Fomento de la Economía Social serviría de contrapeso y control previo en evitación de extralimitaciones o errores nuevos. Las necesidades de desarrollo de la LES son amplias y no sólo en el ámbito de facilitar concreción y vías de articulación práctica de la Ley, sino que deviene imprescindible para su interpretación. Por ello, podríamos decir que una labor de desarrollo resulta útil, aunque, sin embargo, dicha actuación está inédita. Se constata, pues, una radical falta de interés por parte de las administraciones por ejercer en este caso tal capacidad, que tiene atribuida expresa y ampliamente. Tal constatación no debe entenderse como la apuesta por nuestra parte a favor de un ejercicio reglamentario masivo de la LES, sino simple y llanamente como un hecho que demuestra la ausencia absoluta de tal intervención en las materias que se entienden como necesarias. En todo caso, el reglamento ha de concebirse siempre como una norma que está destinada a permitir una correcta aplicación de la Ley, pero cuyo contenido ha de ser el estrictamente "indispensable" para realizar tal función sin agredir el sistema de fuentes y la jerarquía normativa (Sentencias del Tribunal Supremo: 18/6/1982; 28/7/1991).

Como ya hemos señalado, la LES hace referencia expresa a esa potestad reglamentaria en dos ocasiones: el actual artículo 13.5 (antes 9.5) en relación con la regulación del Consejo para el Fomento de la Economía Social y la Disposición final segunda que establece la cláusula habilitadora general en favor del Gobierno "...para dictar cuantas disposiciones sean necesarias para la aplicación y desarrollo de la Ley en el ámbito de sus competencias". Siendo cierto que la Ley es el límite es también verdad que habilitaciones tan genéricas, facilitadas por la propia Ley y, por tanto, cumpliendo sin posibilidad de reproche la legalidad, adquieren un carácter peligrosamente amplio en leyes tan poco explicitas, claras e imperativas como la LES. La elaboración de estos reglamentos ejecutivos, artículo 5.1. h) de la Ley de Gobierno ${ }^{13}$, dota de una capacidad (Muñoz Machado, 1975) que siendo tan enorme resulta ajena al control del poder legislativo parlamentario, estando integrada tranquilamente en ese "dominio reservado y doméstico de la

13 Ley 50/1997, de 27 de noviembre, del Gobierno. BOE núm. 285 de 29 de noviembre de 1997. Modificada por última vez por la Ley 30/2003, de 13 de octubre de Medidas para incorporar la valoración de impacto de género en las disposiciones normativas que elabora el Gobierno. BOE núm. 246 de 14 de octubre de 2003. 
Administración" en palabras de Santamaría Pastor (2004). Aunque, paradójicamente y como hemos dicho, tales peligros parece que no asedian a la LES ya que no se ha iniciado ningún tipo de desarrollo reglamentario a pesar de la amplia habilitación que se otorga al Gobierno.

Si seguimos con detenimiento el texto de la LES advertimos la necesidad de que un gran número de preceptos precisarían de desarrollo reglamentario (por no decir todos). $\mathrm{Y}$ esta necesidad adquiere su preocupante relevancia no solamente porque estaría destinada a desarrollar el detalle de una Ley "minimalista", sino porque, en la mayoría de los casos, se hace imprescindible para aclarar, definir, completar, dar certidumbre, superar carencias y lagunas, precisar e interpretar conceptos, explicar, orientar (palabras todas ellas de Paz Canalejo, 2012). Es decir, afirmamos nosotros, cumplir la finalidad propia de una Ley.

En ese sentido, debemos recordar principios básicos que definen a la norma por excelencia, la Ley, en palabras de García de Enterría y Fernández (1995), como "...la única norma originaria que decide desde sí misma y por sí misma". Siguiendo a estos autores se perfila un concepto metajurídico de la Ley que acentúa su legitimidad última en la voluntad de la comunidad, en la "voluntad general", y ello frente al reglamento como "ocurrencia de los funcionarios" que se materializa en una "norma secundaria, subalterna, inferior y complementaria de la Ley"14. Pero cuando el reglamento se vuelve imprescindible incluso para poder entender la Ley y supera ese estatus subalterno se quiebra el orden jerárquico y se degrada la consideración de la propia Ley. En estos casos serán los reglamentos los que sirvan de referencia real en la materia, supliendo a la Ley y superando ese carácter residual y limitado que, en teoría, la propia Ley les debería asignar. Además, esta constante deslegalización lo que hace es trasladar la capacidad de innovación precisamente al reglamento que, como vemos en este caso, puede ser capaz de derogar leyes formales (García de Enterría-Fernández, 1995).

Uno de los incumplimientos más llamativos de la LES es precisamente el que se refiere a la Disposición transitoria primera ${ }^{15}$. Ya se ha señalado la relevancia que tiene la puesta en marcha del Consejo para el Fomento de la Economía Social conforme a la nueva estructura que plantea la propia Ley en su artículo 13 (antes 9). El papel de este Consejo en el ámbito de la relación con la Administración pública, en su sentido más amplio, es muy importante y a nuestro modo de ver lo es más en su condición de órgano consultivo. No olvidemos que la Ley establece el mandato de su preceptiva consulta en varias ocasiones ${ }^{16}$. Tan relevante función se preservó frente a la necesidad de la reforma del reglamento del Consejo a través de la citada Disposición transitoria, haciendo conservar la vigencia del Consejo para el Fomento ya existente y regulado por lo dispuesto en la disposición adicional de la

14 Esto es, la constatación del principio de jerarquía normativa del artículo 9.3 de la Constitución.

15 La Disposición transitoria primera de la LES establece: "Régimen transitorio aplicable del Consejo para el Fomento de la Economía Social".

Hasta la entrada en vigor del desarrollo reglamentario previsto en el artículo 9.5 de esta Ley, el Consejo para el Fomento de la Economía Social se regirá por lo dispuesto en la disposición adicional segunda de la Ley 27/1999, de 16 de julio, de Cooperativas."

16 En el artículo 6, en relación con la elaboración del Catálogo de los diferentes tipos de entidades integrantes de la economía social. Artículo 13.2 (antes 9.2) sobre las funciones del propio Consejo para el Fomento de la Economía Social. Disposición adicional primera sobre información estadística. Disposición adicional séptima sobre las medidas del Programa de impulso de las entidades de economía social. 
Ley 27/1999, de 16 de julio, de Cooperativas. Pero lo destacable, insistimos, es que no sólo no se ha procedido en estos años a dictar el nuevo reglamento del Consejo sino que la Disposición transitoria tampoco ha entrado en funcionamiento habida cuenta que el Consejo no ha desempañado ninguna de sus funciones en los años que lleva la LES vigente. La última vez que fue convocado fue precisamente para dictaminar sobre el proyecto de la LES. Los niveles de incumplimiento de la Ley en este punto son tan contundentes que ni siquiera se le oyó con respecto a la propia reforma de la LES. Algo sin duda obligado. Por mucho que en su Preámbulo (apartado III) la Ley 31/2015 que reforma la LES se señale que se ha consultado a "las asociaciones intersectoriales representativas...de la economía social...", ello no evita que se esté incumpliendo la LES de manera directa e injustificable. Debemos recordar que el apartado a) del párrafo 2 del artículo 13 (antes, 9) establece como una de las funciones del Consejo para el Fomento de la Economía Social "Informar y colaborar en la elaboración de proyectos sobre cualquier disposición legal o reglamentaria que afecten a entidades de la economía social". No cabe discusión alguna sobre que la reforma de la LES debe incluirse entre el tipo de disposiciones que exige esta intervención previa del Consejo para el Fomento de la Economía Social. Lo cierto es que el precepto no se ha cumplido por la propia LES frente a su reforma, lo que la sitúa en el mundo del despropósito jurídico y a las puertas mismas de su invalidez. Lo mismo le ocurre a las medidas y normas ahora aprobadas en aplicación de la LES, como veremos más adelante. ${ }^{17}$

Por ello es relevante, en el sentido del análisis que planteamos, la reciente reforma de la Ley ya que consideramos, dados los términos en que se ha producido, como algo especialmente negativo. Eso intentaremos demostrar a continuación sobre la base de que tal reforma complica su coherencia, añade inestabilidad normativa y genera inseguridad jurídica. La acción legislativa de su reforma, oculta en otra norma de las denominadas de "medidas", a las que tan acostumbrado se nos tiene, se hace, no lo olvidemos, sobre una Ley "petrificada" en su aplicación, sin recorrido alguno, cuya quietud se ve alterada por la incorporación de varios preceptos que resultan innecesarios a la materia regulada en la Ley y que son más propios, ahora sí, del ámbito reglamentario.

\section{Reforma de la Ley 5/2011 de Economía Social}

Por medio de la Ley $31 / 2015$, de 9 de septiembre, por la que se modifica y actualiza la normativa de autoempleo y se adoptan medidas de fomento y promoción del trabajo autónomo y de la Economía Social se reforma la LES ${ }^{18}$. Es la primera reforma que afecta a esta Ley, añadiéndole varios artículos ${ }^{19}$. Es una reforma que cumple el mandato del Real Decreto-Ley 8/2014, de 4 de julio de medidas urgentes anticrisis y a favor del autoempleo, ratificado posteriormente por el artículo 121 de la Ley 18/2014, de 15 de octubre de aprobación de nuevas medidas urgentes para el crecimiento, la competitividad y la eficiencia. La reforma

\footnotetext{
17 Nos referimos a la parte de la Disposición adicional séptima que se ha cumplido: aprobación de la Ley de sociedades laborales y participadas dentro del Programa de Fomento e Impulso de 20 de julio de 2015.

18 BOE $^{\circ} 217$, de 10 de septiembre de 2015

19 Texto consolidado de la Ley 5/2011, de 29 de marzo, a 10 de septiembre de 2015.
} 
que incorpora la Ley 31/2015, de 9 de septiembre y que afecta a la LES parece tener como causa la necesidad de sistematizar la regulación vigente en materia de incentivos y medidas, reuniéndolas en un solo texto. Sin embargo, tal propósito parece quedar eclipsado de nuevo al articularlo a través de una norma que se dedica a modificar otras de distinto tipo, alejándose de una real sistematización y creando confusión e inseguridad. No olvidemos, por lo demás, que la mayoría de estas regulaciones en cascada que abocan a la reforma de la LES forman parte de las citadas "leyes de medidas" que, por lo general, adquieren la forma de Decretosleyes, esto es, normas jurídicas que no han seguido los trámites normales que aseguran una intervención parlamentaria plena.

Esta Ley de reforma aporta de entrada una curiosidad en su preámbulo, concretamente en el apartado II, al justificar los cambios en la LES y también, con el mismo argumento, en la Ley 20/2007, de 11 de julio, del Estatuto del Trabajo Autónomo, sobre que la "aplicación en la práctica de sus preceptos ha demostrado la existencia de diversos aspectos cuya regulación es ineficaz o susceptible de mejora o desarrollo". Desde luego, si se parte del dato irrefutable de que la LES ha tardado mucho en aplicarse mínimamente y no se ha desarrollado reglamentariamente en absoluto, sólo podemos concluir, con perplejidad indisimulada, que tal necesidad de retoque y mejora no queda justificada de ningún modo en esta operación. El valor de los preámbulos de las leyes es menor ya que aunque forma parte integrante de las normas no alcanzan naturaleza normativa, ni pueden considerarse genuina motivación y su valor interpretativo suele ser limitado (Ezquiaga, 1988; Diez-Picazo, 1992;)20. Pero esta parte inicial de la mayoría de las leyes, también en algunos reglamentos, no deja de tener algún valor. En palabras de Diez-Picazo "Los preámbulos, por consiguiente, únicamente pueden ser configurados hoy en día como un mecanismo que facilita la efectividad de la responsabilidad política difusa del Parlamento ante los ciudadanos... Cierto es que se trata de un modesto instrumento; mas no por ello debe ser despreciado, sobre todo, si se tiene presente que nada es poco en la labor de racionalización del ejercicio del poder y en la, tampoco desdeñable, tarea de favorecer la buena técnica legislativa." Para otros autores (Bonachela Mesas, 2011) los preámbulos incorporan cierta función pedagógica. Por ello, que lo señalado en el preámbulo no concuerde con el texto normativo posterior también define de algún modo la responsabilidad del legislador y la plasmación de una mala técnica legislativa. Hubiera sido útil explicitar mínimamente qué aspectos de la LES han resultado ineficaces y por qué y cuáles son susceptibles de mejora o desarrollo. La reforma no introduce mejoras del texto ni sustituye supuestos aspectos ineficaces, ni

20 Este criterio sobre el valor de los preámbulos se ha generalizado en la doctrina y el propio Tribunal Constitucional lo ha concretado en distintas ocasiones (Sentencias: 36/81, de 12 de diciembre, 132/1989, de 18 de julio, 150/1990, de 4 de octubre y 212/1996, de 22 de enero. O la destacada sentencia 31/2010, de 28 de junio relativa al recurso de inconstitucionalidad frente al Estatuto Catalán), doctrina que no niega cierto valor interpretativo a los preámbulos en el sentido de que incluso pueden servir para asentar una valoración de inconstitucionalidad al vincularlo con los artículos específicos posteriores de la Ley. De ese modo, el valor interpretativo que el preámbulo incorpora, si bien se presenta como liviano, a veces puede resultar útil. Así lo demuestra, por ejemplo, la sentencia del Tribunal Superior de Justicia de la Comunidad Valenciana, ratificada por el Tribunal Supremo, número 77/2009, de 27 de enero, por la que el preámbulo sirve para interpretar el articulado de la Ley de manera concreta cuando éste se plasmaba bajo un concepto jurídico indeterminado. Por tanto, cierto valor interpretativo puede advertirse. 
practica el desarrollo de la norma. Ello impide conocer con una mínima certeza cuál ha sido la verdadera ratio legis de tal reforma. Lo que si es cierto es que la reforma aplicada no hace a la Ley más eficaz, al contrario. No la mejora en absoluto, más bien entorpece su capacidad de desplegar algunas potencialidades.

La Ley 31/2015, de 9 de septiembre, en lo que afecta a la LES, introduce las modificaciones a través de su artículo tercero y lo hace de un modo técnicamente perfectible ya que incorpora una serie de preceptos que llaman a la confusión permanente, a la incoherencia interna y abocan a la inseguridad jurídica. Gran parte de esas modificaciones son cuestiones de orden práctico que bien pudieran haberse regulado mediante simples decretos al ser medidas coyunturales, muy concretas o propias de una norma distinta a la LES. Como advertía ya en 1995 Calvo Charro es necesario que la Ley “...se vea liberada de detalles y regulaciones accesorias, técnicas, coyunturales o pobres en contenido decisional político; cediendo tal labor a la potestad reglamentaria del Gobierno". Además, el formato empleado introduce también un inequívoco componente de falta de homogeneidad fruto de una desconexión directa entre los elementos que configuran el texto inicial de la LES y estos añadidos introducidos por la reforma.

Bien es verdad que la posición preponderante que asumen en general las Leyes en cuanto a rango en el sistema de fuentes hace que pueda aplicarse el aserto de que quien puede lo más puede lo menos. En ese sentido, a las leyes no les está vedada la posibilidad de regular materias que anteriormente han sido atribuidas a los reglamentos ya que no se contempla la reserva material en favor de éstos. Por ello, no es infrecuente que se produzca la elevación del rango y su congelación en materias que antes estaban deslegalizadas. ${ }^{21}$ Pero lo que sucede con la LES es una contradicción difícil de asimilar y que consiste en que aquello que sí debiera ser regulado por la potestad reglamentaria no se hace y, por contra, lo que hasta ahora estaba deslegalizado se eleva de rango, pero momentáneamente ya que se añade un elemento aún más extraño, como veremos a continuación, estableciendo materias que en la reforma asumen rango legal al tiempo que se permite su modificación a través de la potestad reglamentaria. Este confusionismo de rangos normativos no favorece una consideración favorable de la LES. Como señalan García de Enterría y Fernández (1995) el reglamento es una "norma secundaria, subalterna, inferior y complementaria de la Ley, obra de la Administración". La técnica legislativa que se viene aplicando en este caso, con la LES, consigue confundir y equiparar a la Ley con el reglamento, hasta el punto de no poder distinguir en algunos supuestos qué es una cosa y qué es la otra desde el punto de vista material. Eso no se produce solamente en la reforma operada en la LES sino que viene siendo algo frecuente en otras normas integradas en el ámbito de las entidades de la ES (Paniagua, 2013) ${ }^{22}$. Hay que preguntarse hasta qué punto se están respetando realmente los principios de jerarquía normativa y seguridad jurídica que consagra la Constitución en su artículo 9.3. O si este proceder, por extensión, asume el criterio de la "legislación adecuada" que contiene el artículo 129.2 del texto constitucional.

21 El Tribunal Constitucional se ha pronunciado en este sentido en varias ocasiones. A modo de ejemplo las sentencias: 5/1981, de 13 de febrero. FJ 21b); 73/2000, de 14 de marzo. FJ 15; 104/2000, de 13 de abril. FJ9 ó 120/2014, de 17 de julio. FJ 8.

22 Paniagua Zurera, refiriéndose a la reforma de la Ley 14/2011, de 23 de diciembre, de Sociedades Cooperativas Andaluzas. 


\subsection{Modificación del artículo 5 de la LES}

El apartado Uno del referido artículo tercero modifica la LES en su artículo 5, añadiéndole un apartado 4. Se refiere a la declaración como "entidades prestadoras de Servicios de Interés Económico General, los Centros Especiales de Empleo y las Empresas de Inserción, constituidas y calificadas como tales según su normativa reguladora. Asimismo, podrá extenderse esta declaración a cualesquiera otras entidades de la economía social que tengan por objeto igualmente la inserción laboral de colectivos en riesgo de exclusión, conforme a lo que se establezca reglamentariamente." No puede oponerse ningún argumento a la declaración que se hace a favor de los Centros Especiales de Empleo y Empresas de Inserción como "entidades prestadoras de Servicios de Interés Económico General". Al contrario, es una determinación útil. Sin embargo, lo que no se compadece bien con una correcta sistemática normativa es el juego permanente de rangos del que adolece este apartado 4 . Por un lado, congela en rango legal la declaración en favor de los Centros Especiales de Empleo y las Empresas de Inserción, pero el propio texto abre tal posibilidad al resto de entidades de la ES "conforme a lo que se establezca reglamentariamente". No se entiende bien que para unas figuras se empleé la Ley mientras que para otras valga con el reglamento.

Esta distinción de rango normativo puede suponer la creación de situaciones de inseguridad jurídica que podrían plantearse, antes o después, con posibles consecuencias conflictivas. No puede sino calificarse de foco de confusión de fuentes y de materias objeto de distinto tratamiento y con origen en competencias normativas también diferentes que resulta muy difícil de explicar desde un análisis de técnica jurídica. No cabe duda de que esta declaración como entidades prestadoras de servicios de Interés General tiene la finalidad de cumplir con las determinaciones que en la regulación de la Unión Europea sobre contratación pública se han venido dictando. En efecto, la Directiva 2014/23/UE sobre contratos públicos de concesión, introduce la necesidad de atender criterios sociales, cláusulas sociales, en la adjudicación de contratos, estableciendo en su artículo 24 la posibilidad de concesiones "reservadas" a entidades de empleo protegido. Pero no limita a éstas tal posibilidad, sino que determina expresamente la consideración de las entidades y empresas de la ES como "operadores económicos" a los efectos de las normas de contratación pública. Por tanto, puede pensarse que una distinción en el rango a la hora de tratar unas y otras no es lo más adecuado. Por su parte la Directiva 2014/24/UE sobre contratación pública, coincidiendo en lo que se refiere a las cláusulas sociales (artículo 67), establece la posibilidad de contratación "reservada" a entidades de empleo protegido (artículo 20) pero ampliando el espectro en cuanto a contratos sobre determinados servicios sociales "reservados" a empresas y entidades con características propias de la ES (artículo 77). La Directiva 2014/25/UE sobre contratación pública en sectores de agua, energía, los transportes y los servicios postales también determina la posibilidad de contratos "reservados" a entidades de empleo protegido (artículo 38).

Entendemos que si bien las determinaciones constantes en estas directivas comunitarias se refieren a las empresas y entidades de empleo protegido, también se extienden, como hemos señalado antes, a otras empresas y entidades de la ES. Hubiera sido una gran oportunidad equiparar en la Ley española a todas las figuras 
sin tener que ser testigos de este innecesario baile de rangos. El conflicto del que hablamos hace un momento se hace más posible precisamente con respecto al artículo cuarto de la Ley 31/2015, que incluye la reforma de la LES, ya que introduce una modificación de la disposición adicional quinta del Texto refundido de la Ley de Contratos del Sector Público, aprobado por el Real Decreto Legislativo 3/2011, de 14 de noviembre. Esta disposición hace referencia a los "contratos reservados" 23 en favor de Centros Especiales de Empleo y Empresas de Inserción, pero no al resto de la ES. Lo que sin duda puede consolidar una prelación entre unas y las otras basada en esta determinación de la Ley de Contratos del Sector Público y la diferencia de tratamiento normativo, de rango, que la reforma de la LES establece. Recordemos que la LES abre la posibilidad al resto de entidades de ES mediante la potestad reglamentaria frente a la Ley de Contratos del Sector Público que lo limita a las antecitadas dos figuras de empleo protegido. Otra vez reglamento frente a Ley. Ley frente a Ley. En definitiva, más dosis de confusión.

Lo cierto es que no tiene ningún sentido forzar de este modo el sistema de fuentes, introduciendo la sensación de que las leyes han perdido su relevancia pues daría lo mismo uno que otro tipo de norma ya que ambas, la Ley y el reglamento, son de obligado cumplimiento general. El conflicto, como decimos, está servido.

\subsection{Modificación del artículo 9 de la LES. "Incentivos a la incorporación de trabajadores a entidades de la economía social"}

El apartado Dos de este artículo Tercero que establece la reforma de la LES, traslada el entonces vigente artículo 9, por el que se regula el Consejo para el Fomento de la Economía Social, al 13. En este reformulado artículo 9 se regulan bonificaciones aplicables a las entidades de ES en cuotas empresariales y de la Seguridad Social. De entrada, no entendemos que estas medidas coyunturales se hayan plasmado con rango de Ley. Es innecesario, pues se establecen medidas que incluyen cálculos precisos y cifras al céntimo que al ser congeladas en este rango legal precisarían para su alteración o simplemente acomodación a las circunstancias que puedan sobrevenir, un procedimiento legislativo de modificación de la Ley (o no, como descubriremos). Con ello, se le somete a un

23 Esta Disposición adicional quinta queda redactada como sigue: “Contratos reservados.

1. Mediante Acuerdo del Consejo de Ministros o a través del órgano competente en el ámbito de las Comunidades Autónomas y de las Entidades Locales, se fijarán porcentajes mínimos de reserva del derecho a participar en los procedimientos de adjudicación de determinados contratos o determinados lotes de los mismos a Centros Especiales de Empleo y a empresas de inserción reguladas en la Ley 44/2007, de 13 de diciembre, para la regulación del régimen de las empresas de inserción, que cumplan con los requisitos establecidos en dicha normativa para tener esta consideración, o un porcentaje mínimo de reserva de la ejecución de estos contratos en el marco de programas de empleo protegido, a condición de que el menos el 30 por ciento de los empleados de los Centros Especiales de Empleo, de las empresas de inserción o de los programas sean trabajadores con discapacidad o en riesgo de exclusión social.

En el referido Acuerdo del Consejo de Ministros o a través del órgano competente en el ámbito de las Comunidades Autónomas y de las Entidades Locales, se fijarán las condiciones mínimas para garantizar el cumplimiento de lo establecido en el párrafo anterior.

2. En el anuncio de licitación deberá hacerse referencia a la presente disposición.” 
desgaste impropio y muy nocivo para una norma que se aplica con dificultad y no se desarrolla reglamentariamente. Esta acción añade más confusión e inseguridad. Recordemos que medidas similares a las que se incorporan a la Ley en el terreno de las bonificaciones en cuotas a la Seguridad Social y sobre cobro de prestaciones han sido vehiculizadas en muchas de las ocasiones a través de reales decretos ${ }^{24}$. Es lógico hacerlo así ya que la evolución de los parámetros económicos o del empleo o el paro son constantes, a veces cíclicos y otras poco predecibles. Tales coyunturas entran de lleno en el ámbito de las llamadas "medidas" de política económica y social que difícilmente pueden formar parte de contenidos de normas que se definen por su propósito de permanencia y generalidad. Las leyes deberán establecer, como emanación directa y soberana del poder legislativo, los límites o principios que enmarquen tales medidas pero no necesariamente el detalle pormenorizado de las mismas ${ }^{25}$. Y menos aún con la nociva estrategia de reformar o derogar varias leyes al mismo tiempo mediante la aprobación de "leyes de medidas" que convierten el universo normativo en un insufrible pozo de confusión e inseguridad o, en palabras de Paniagua (2013) en un "frondoso bosque legal". Como ejemplo de lo que decimos puede señalarse el apartado 2 de este nuevo artículo $9 .{ }^{26}$

\subsection{Nuevo artículo 10. “Capitalización de la prestación por desempleo a los beneficiarios de prestaciones cuando pretendan incorporarse como socios trabajadores o de trabajo en cooperativas o en sociedades laborales."}

En similares términos críticos, o con mayor razón si cabe, hemos de referirnos al nuevo artículo 10 de la reformada LES. A los efectos del análisis que estamos realizando no abordamos las medidas concretas que se incorporan ya que no son objeto de nuestro estudio. La crítica que afloramos se refiere a la cuestión sobre la necesidad de incluir estas medidas en la Ley, y más en concreto, en esta Ley. Como en el caso del artículo 9, ya señalado antes, creemos que es un error. Pero el grueso

24 Se pueden señalar precedentes concretos en sentido de lo que decimos:

.-Real Decreto 1044/1985, de 19 de junio por el que se regula el abono de la prestación por desempleo en su modalidad de pago único por el valor actual de su importe, como medida de fomento del empleo.

-- Real Decreto 1975/2008, de 28 de noviembre, sobre las medidas urgentes a adoptar en materia económica, fiscal, de empleo y de acceso a la vivienda.

.- Real Decreto 1.300/2009, de 31 de julio, de medidas urgentes de empleo destinadas a los trabajadores autónomos y a las cooperativas y sociedades laborales.

25 En la propuesta de borrador de texto legal sobre la LES elaborada por la Comisión de Expertos designada por el Gobierno, se incluía en el ámbito del desarrollo de las políticas de fomento de la ES referencias genéricas, no pormenorizadas, relativas a medidas como exenciones, reducciones o bonificaciones tanto en las cotizaciones a la Seguridad Social como en el ámbito tributario (artículo 10 de la propuesta, apartados c) y d)). Es lo más correcto. Lo que no se hizo fue detallar en el texto las medidas posibles. En todo caso, la propuesta no fue incluida en el texto final.

26 El artículo 9.2 dice textualmente: "En relación al apartado 1.a), se aplicará lo establecido en la sección I del capítulo I de la Ley 43/2006, de 29 de diciembre, para la mejora del crecimiento y del empleo, salvo lo establecido en su artículo 6.2 .

En lo no previsto en el apartado 1.b), se aplicará lo establecido en la sección I del título I de la Ley 43/2006, de 29 de diciembre, para la mejora del crecimiento y del empleo, en cuanto a los requisitos que han de cumplir los beneficiarios, las exclusiones en la aplicación de las bonificaciones, cuantía máxima, incompatibilidades o reintegro de beneficios".

Si se permite el comentario, el texto nos recuerda alguno de los más ingeniosos diálogos de los hermanos Marx. 
de la oposición a esta actuación se centra, como antes, en la confusión de rangos normativos. Comienza el artículo 10, en su apartado 1, sometiéndonos a una nueva aventura interpretativa al vincularse con un Real Decreto (RD 1044/1985, de 19 de junio) que ya reguló la materia de la prestación por desempleo en su modalidad de pago único. Textualmente dice que se “...mantendrá lo previsto en...” dicho Real Decreto, incluidas “...las modificaciones incorporadas por normas posteriores, en lo que no se oponga a las reglas siguientes...”. Más confusión, incoherencia y, como consecuencia, inseguridad jurídica (sobre todo teniendo en cuenta la pretendida intención sistematizadora que el Preámbulo anuncia). Lo que se nos está insinuando por la propia LES es que la materia regulada por este nuevo artículo es propia del reglamento pero que para este caso se eleva el rango y que esta materia regulada es volátil, sujeta a constantes reformas, precisamente por referirse a medidas coyunturales como ya se ha dicho y que no son propias de una Ley con voluntad de permanencia. El rango legal en este caso es prácticamente irrelevante.

Pero vuelve a producirse la mareante y desagradable sensación de "montaña rusa" que invade esta reforma al señalarse en el apartado 2 de este nuevo artículo 10 que "El Gobierno podrá modificar, mediante real decreto, lo establecido en el apartado 1 anterior". Por tanto, se modifica la LES para incorporar una regulación de contenido menor atribuyéndole un rango formal de Ley que puede alterarse por simple decreto. Es decir, un proceso deslegalizador que transita por el absurdo y que, volviendo a utilizar palabras de Paniagua (2013) hace que el jurista se mueva "entre la sorpresa y el estupor".

\subsection{Nuevo artículo 11. "Bonificaciones de cuotas de Seguridad Social para los socios trabajadores o socios de trabajo de las sociedades cooperativas, en período de descanso por maternidad, adopción, acogimiento, riesgo durante el embarazo, riesgo durante la lactancia natural o suspensión por paternidad."}

Sin ánimo de ser exhaustivo podemos hacer las mismas consideraciones anteriores con respecto al nuevo artículo 11 que incorpora la reforma. Sin negar la necesidad de las medidas, seguimos considerándolas mal ubicadas.

\subsection{Nuevo artículo 12 "Pago único de la prestación por cese de actividad"}

Lo mismo ocurre con el nuevo artículo 12. Simplemente haremos una breve consideración, en concordancia con lo dicho hasta ahora, a lo establecido en el apartado 8 de este artículo ${ }^{27}$ ya que vuelve a mezclar, creemos que equiparándolos, el texto con rango de Ley con lo que se establece por Real Decreto, en desarrollo de una tercera Ley dedicada al establecimiento de un sistema específico para los trabajadores autónomos que, como todo el mundo sabe, hoy por hoy no forman per sé parte de la ES. Más confusión.

27 El apartado 8 del artículo 12, señala: “ La no afectación de la cantidad percibida a la realización de la actividad para la que se haya concedido será considerada pago indebido a los efectos previstos en el artículo 31 del real Decreto 1541/2011, de 31 de octubre, por el que se desarrolla la Ley 32/2010, de 5 de agosto, por la que se establece un sistema específico de protección por cese de actividad de los trabajadores autónomos. A estos efectos, se entenderá, salvo prueba en contrario, que no ha existido afectación cuando el trabajador, en el plazo de un mes, no haya acreditado los extremos indicados en el apartado 4 de este artículo". 


\subsection{Nuevo artículo 13 y modificación de la disposición final primera}

Para finalizar este apartado señalamos que la reforma establece, como se ha dicho ya, que la materia regulada en el anterior artículo 9 pasa al 13 sin alteración alguna en su literalidad. La reforma se completa con una nueva referencia en la Disposición final primera relativa al título competencial al considerar los nuevos artículos 9,10,11 y 12 legislación básica por ser materia afectante a la regulación básica y régimen económico de la Seguridad Social.

De lo visto hasta ahora puede avanzarse alguna conclusión sobre que además del incumplimiento de la LES se añaden su procelosa deslegalización y, al tiempo, la congelación del rango legal de materias propias del reglamento (a veces ambas cosas a la vez). Proceso deslegalizador que no se concreta en un desarrollo reglamentario específico y en el que las atribuciones de rango quedan sometidas al albur de posibles decisiones reglamentarias. Tal sinuosidad aboca a la LES a ser considerada como una ley conflictiva, por su escasa capacidad de producir efectos y consecuencias directamente y por su imprecisión.

Siguiendo a Santamaría Pastor (2004) la "fuerza de la Ley" se concreta, en el marco del Ordenamiento Jurídico, en tres aspectos generales: a) su capacidad de innovación sobre el conjunto del sistema normativo, al tener la posibilidad de modificar o derogar normas de igual o inferior rango; b) cierta resistencia pasiva a la innovación si no es por otra norma de igual o superior rango y competencia. Reconociendo la existencia de leyes afectadas por procesos deslegalizadores que hacen perder esa característica resistencia a la modificación y c) el principio por el que los poderes del Estado en ningún caso podrían dejar de aplicarla. Si proyectamos estos tres parámetros sobre la LES de un modo directo y riguroso no podemos dejar sentado que se cumplan. Por un lado, porque esa capacidad de innovación entendida como la capacidad de derogar o modificar normas anteriores es prácticamente nula. Precisamente una de las señas de identidad de la LES es que no produce alteración alguna en el sistema normativo ya que expresamente consolida el respeto a las regulaciones preexistentes en la materia que regula (art. $1)^{28}$. Ello se confirmaría en la inexistencia de ningún tipo de disposición derogatoria. Aunque la reforma que comentamos nos vuelve a introducir en un brumoso espacio donde se atribuyen posibles efectos derogatorios precisamente en el ámbito de futuros reglamentos que mantendrían su vigencia incluso sobre la propia Ley.

En segundo lugar, la resistencia pasiva a la innovación ya vemos que tampoco puede predicarse de esta Ley, esencialmente por dos razones: una, porque ya ha sido reformada sin apenas haberse comenzado a aplicar y, dos, porque es una Ley con una exigua capacidad de resistencia al cambio. El fenómeno de la "deslegalización", por el cual una norma con rango de Ley pierde su resistencia a

28 Artículo 1. "Objeto. La presente Ley tiene por objeto establecer un marco jurídico común para el conjunto de entidades que integran la economía social, con pleno respeto a la normativa específica aplicable a cada una de ellas, así como determinar las medidas de fomento a favor de las mismas en consideración a los fines y principios que le son propios". Teniendo en cuenta lo que señalaba Fajardo (2009), sin duda se ha perdido una ocasión indiscutible para haber abordado reformas de leyes sectoriales o regular cuestiones pendientes en el ámbito de la ES. 
sucesivas alteraciones, ya que parte de ella puede ser regulada por normas reglamentarias, se convierte en la característica que define a la LES.

La deslegalización se proyecta esencialmente sobre la capacidad normativa de la Administración pública que asume una tarea que abandona el espacio propio del legislador parlamentario. El papel que la Administración ha adquirido en cuanto al desarrollo de esta capacidad viene siendo ampliamente criticado por la doctrina ya que la creación de normas jurídicas se está materializando en un proceso que se sitúa extramuros de la labor propia del poder legislativo. En el caso de la LES este proceso deslegalizador se advierte ya desde el principio (Paz Canalejo, 2012) y se ha concretado con esta primera reforma que sufre, tal y como venimos señalando.

Ello se confirma con el "cambio de sitio" que ha afectado a la regulación del Consejo para el Fomento de la Economía Social. No ya por esta alteración digamos geográfica sino por lo que supone de agria metáfora sobre el desvalor que la LES viene adquiriendo como consecuencia de su nulo cumplimiento. Ya se ha dicho (Pérez De Uralde, 2014) que en este tema del Consejo para el Fomento de la Economía Social el grado de vulneración de la norma es ya inaceptable (si es que el resto puede o debe aceptarse).

Y un tercer rasgo es la imposibilidad de que los poderes del Estado puedan dejar de aplicarla. Como ya se ha señalado antes con cierta reiteración, la aplicación de la LES ha resultado muy tardía y limitada y su directa vulneración o incumplimiento es evidente en varios de sus mandatos. Siendo esto así podría afirmarse que de facto la Ley carece de las características propias que invisten el concepto de "fuerza de Ley", lo que supone una evidencia especialmente lamentable y nos permite ir avanzando las calificaciones de "ley blanda" y "norma imperfecta".

\section{La regulación legal de la Economía Social. Entre la Ley formal y el "derecho blando"}

Llegados a este punto consideramos obligado afrontar cierta recopilación de argumentos y evidencias para intentar explicar algunas aparentes contradicciones que hemos provocado. Hemos intentado describir una realidad sustentada en el derecho positivo, la LES, que ha de proyectarse sobre un proceso valorativo de la norma que intentamos concretar en atención a su devenir vital.

Hasta ahora hemos constatado que, además de una falta de aplicación de la LES, se define una característica muy marcada en ella que podemos situar dentro de un proceso de deslegalización (regulación mediante reglamentos) con clara proyección de futuro. Al tiempo, denunciamos una falta de desarrollo reglamentario. Esta contradicción, que ciertamente es más aparente que real, merece ser convenientemente explicada.

La falta de desarrollo reglamentario es una crítica inevitable ya que se produce sobre un mandato legal expreso de la propia LES en su artículo 13 (antes 9). También porque su efectivo cumplimiento hubiera permitido que en algunas materias la ley hubiera podido desplegar algunas potencialidades prácticas (efectiva intervención del Consejo para el Fomento de la Economía Social y elaboración del catálogo de entidades). Sin embargo, el hecho de que la LES 
precise de desarrollo sobre mandatos concretos y esto sea lisa y llanamente incumplido nos sitúa frente a una anomalía de indudable trascendencia en la valoración de la norma en su conjunto, tanto desde un prisma estrictamente dogmático como socio-político. El primero es el que ahora nos ocupa. Por ello, no cabe sino afirmar que la LES precisa de un desarrollo reglamentario que regule de una vez el nuevo Consejo para el Fomento de la Economía Social y el Catálogo de Entidades. Son dos materias imprescindibles para el cumplimiento de la norma ya que su puesta en marcha dará valor real a la efectividad de la LES, mientras que su incumplimiento insistente la seguirán debilitando y degradando. Debilitando porque la puesta en funcionamiento de estas dos cuestiones ayudará a consolidar una ES con presencia y voz institucional y con cobertura formal para aquellas decisiones y normativas que precisara de su concurso (Consejo) o de su existencia $(\text { Catálogo })^{29}$. Y degradando porque tal incumplimiento flagrante de un mandato legal la condiciona en su efectividad y en su consideración como tal norma. Por tanto, ese desarrollo mínimo es imprescindible y urgente.

La realidad nos demuestra que la LES no acaba de desplegar ningún efecto, que su peso específico es muy débil. En ese sentido, la reciente reforma de la LES que hemos comentado, lejos de resolver ese tipo de problemas de falta de efectividad incurre, a nuestro modo de ver, en todo lo contrario. A la LES se le incorporan elementos realmente innecesarios a su configuración como norma con rango de Ley y se hace, además, con un permanente juego de referencias cruzadas hacia otras normas, pasadas, presentes y futuras, de distinto rango que, como ya hemos señalado, acaban en un claro proceso deslegalizador donde es el reglamento el que adquiere la verdadera preponderancia. Al día de hoy, la LES está en manos de "posibles" desarrollos reglamentarios en materias que la reforma presenta con rango formal de Ley, operándose un resultado final que deslegaliza formalmente y reduce el carácter imperativo de su contenido, lo que ya se viene advirtiendo en cuanto a otras leyes sobre entidades de la ES (Paniagua, 2013).

Nuestra opinión es que el desarrollo reglamentario es imprescindible e inderogable, lo repetimos, en relación a los mandatos de la propia Ley y quizá sobre otras materias específicas. Pero que la reforma efectuada en los términos que hemos descrito es una deslegalización encubierta que en nada ayuda a una consideración positiva de la LES. Esta reforma ultima un proceso que tras la incomprensible falta de aplicación la viene a colocar en los lindes mismos de la ineficiencia más absoluta. Se apuntan rasgos que la sitúan fuera del concepto material y formal de norma "con fuerza de Ley" y dentro, quizá, de otra categoría. Una Ley sin valor de Ley. Una "Ley blanda". Recordemos que incluso los desarrollos o efectos prácticos de los mandatos contenidos en la Disposición adicional séptima se articulan por medio de un instrumento denominado

29 Hay que tener muy en cuenta lo que establece la Disposición adicional primera de la Ley 5/2011 sobre la trascendental cuestión de la información estadística de las entidades de la ES: “El Ministerio de Trabajo e Inmigración adoptará, en colaboración y coordinación con los departamentos ministeriales y las Administraciones que pudieran tener competencia en materia registral de las entidades de la economía social, y previo informe del Consejo para el Fomento de la Economía Social, las medidas necesarias para garantizar una información estadística de dichas entidades así como de sus organizaciones de representación, periódicamente actualizada y ajustada en su clasificación al catálogo previsto en el artículo 6 de esta Ley." Sin Consejo y sin catálogo esta Disposición forma parte del nada digno club de las normas incumplidas. 
"Programa de impulso de las entidades de la economía social" que formalmente carece de valor normativo. Quizá toda la LES sea en realidad un "programa de impulso y fomento de la Economía social" que se inscribiría, sin duda, en lo que se ha considerado como "derecho blando" o "soft law".

Desde un prisma estrictamente teórico, y también estrictamente formal, el denominado "derecho blando" se constituye por actuaciones y pronunciamientos con base jurídica que carecen de carácter imperativo u obligatorio, pero que se incorporan de una u otra manera al sistema de fuentes (Sarmiento, 2006). Por ello, se ha venido señalando como derecho "suave" o "débil" frente al derecho "fuerte" que incorpora consecuencias cuando se produce su incumplimiento. Su origen moderno surge en el ámbito del Derecho Internacional, fundamentalmente de las organizaciones internacionales que con frecuencia dictan resoluciones normativas que carecen de fuerza vinculante y de efectos jurídicos directos. Como señala Alarcón García (2010) "Bajo este término se recogen actos o instrumentos jurídicos sin carácter obligatorio para incardinarlos en el sistema de fuentes, tales como recomendaciones, resoluciones, instrucciones, planes, circulares, normas técnicas, cartas de servicios, códigos de conducta o de buen gobierno, entre otros, cuyo elemento común es el de causar dificultades al intérprete del derecho". Por tanto, además de la nota característica de tener cierta relevancia jurídica pero no efectos vinculantes, constituye un espacio jurídico proclive a causar problemas de interpretación.

Una estricta concepción teórica de este tipo de producción del Derecho impide considerar a las leyes formales como parte del mismo. Por definición, como hemos indicado antes, una Ley formal es la demostración más clara de la fortaleza legislativa. Sin embargo, ya algunos autores vienen señalando posibilidades en cuanto a que tal dicotomía, Ley formal versus norma no imperativa, no siempre es tan sólida. Se mencionan en tal sentido aquéllas normas que se componen tanto de reglas taxativas y obligatorias como de determinaciones principiales cuyo cumplimiento es susceptible de no estar determinado por la propia norma, siendo considerado como "mandatos de optimización". El cumplimiento de estos mandatos resulta indeterminable, graduable según las circunstancias tanto reales como jurídicas (Atienza y Ruíz, 1996 ; Alexy, 2001).

Con respecto a estas normas de "derecho blando", Sarmiento (2006) se refiere a aquéllas que teniendo carácter formal de leyes responden a ese perfil regulador de "principios" más que de "reglas". Nos habla de las "Leyes manifiesto", "...sin contenido normativo definido como consecuencia de su indeterminación, pero que cuentan con una indudable categoría de "hard law" " (derecho fuerte). Por ello, podríamos hablar de un "tertium genus" que se mueve entre uno y otro concepto teórico y cuya especial caracterización es la indeterminación, tan impropia de una Ley formal, y la falta de consecuencias por su inaplicación, también ajeno al concepto de Ley.

Si proyectamos estas propuestas al contenido de la LES, tanto a su falta de aplicación como de desarrollo y, también, a la deficiente reforma que ha padecido, podemos asumir que los perfiles que nos ofrece pueden coincidir en gran medida con este concepto que define este tipo de Ley formal pero preponderantemente declarativa. Una Ley de principios, con grandes dosis de indeterminación, con una indudable necesidad de mejora técnica y que no parece ofrecer nada más allá de 
una declaración de principios y, eso sí, la constatación de que por fin la ES es una realidad también en el plano legal. Lo que siendo crucial queda minimizado por su incapacidad de desplegar efectos ${ }^{30}$.

La LES es una Ley de fomento e impulso que en su mayor parte carece de determinaciones de "derecho fuerte" y que se mueve también en el ámbito de los "principios" y los pronunciamientos que carecen de efectos directos. No cabe duda de que en materia de ES se está produciendo una exagerada tendencia a combinar las características del "derecho blando" y el "fuerte". Se vuelven demasiado declarativas y no siempre es posible pensar en una fácil aplicación ${ }^{31}$. Si a ello sumamos la realidad que hemos descrito anteriormente sobre su escasa aplicación en los pocos mandatos que contiene, su absoluta falta de desarrollo reglamentario y el nefasto galimatías de rangos legales que su reforma propicia, solo podemos concluir que difícilmente se aprecia la presencia de "fuerza de Ley". Que resulta muy complicado hablar de "derecho fuerte". Quizá se mantiene la LES en un espacio que reúne las características de ambos tipos de normas jurídicas, esto es, la formalidad de la Ley y la falta de efectos. Recordemos que ya en el Derecho Romano se conocía esta forma de legislar como "lex imperfecta" (Betancourt, 2007) o "norma imperfecta" en términos contemporáneos.

Un elemento que ayuda a mantener esta tesis por nuestra parte podemos referirlo a que entre los instrumentos jurídicos que en el marco del Derecho Público se pueden incluir en la categoría de "derecho blando" se incluyen los llamados "Programas" que aprueba la Administración. Instrumentos que con una clara finalidad regulatoria, ya que por lo general pueden promover o provocar desarrollos normativos y actos administrativos de aplicación, no son normas jurídicas en sentido estricto. No son leyes ni reglamentos. Como señala el artículo 24 de la ya citada Ley de Gobierno las formas que revisten las decisiones del Ejecutivo de la Nación son: Reales Decretos Legislativos; Reales Decretos Leyes; Reales Decretos del Presidente del Gobierno; Reales Decretos del Consejo de Ministros; Acuerdos del Consejo de Ministros que no deban adoptar la forma de Real Decreto; Ordenes del Ministro competente, según la materia, sobre acuerdos de las Comisiones Delegadas del Gobierno y Órdenes Ministeriales correspondientes a los Ministros.

Como ya hemos señalado, la LES incorpora la figura del Programa de Impulso en su disposición adicional séptima incluyendo medidas directamente efectivas en aplicación de la LES (vid nota 3) y que del mentado Programa pueden derivarse producciones normativas con rango de Ley o con efectos sobre leyes vigentes. Es curioso que el instrumento que supone un mecanismo de efectividad de la LES corresponda a ese mundo nebuloso del "derecho blando". El acto formal que activa el Programa de Impulso no tiene la calidad de norma jurídica pues no se incluye en ninguna de las formas que la Ley de Gobierno (artículo 24) considera

30 El mismo Sarmiento nos indica un precedente en este sentido en la Ley 51/2003, de 2 de diciembre de igualdad de oportunidades, no discriminación y accesibilidad universal de las personas con discapacidad y señala que "A lo largo de su articulado, las disposiciones cuentan, con antecedentes y consecuentes indeterminados, a lo que debe sumarse la inexistencia de sanciones en caso de incumplimiento". Y como muestra de la indeterminación de las normas de esta Ley señala el articulado que regula las "Medidas de fomento y defensa".

31 En cierta medida sucede los mismo con la Ley 43/2015, de 9 de octubre del Tercer Sector de Acción Social, donde la parte meramente declarativa se superpone sobre cualquier otro aspecto. 
como tales. Ni siquiera cabría hablar de un "reglamento impropio" ya que carece del refrendo formal del Gobierno, entendido este en sentido estricto, en el sentido que la Ley atribuye a la capacidad de ejercer la potestad reglamentaria (Tribunal Supremo: 6/11/1984; 23/2/1993; 13/10/2011; 4/11/2011 y 14/11/2011). Es más, surge de una decisión que contraviene directamente lo que la LES prescribe en su Disposición adicional séptima. Esta disposición señala que será el Gobierno quien apruebe el Programa de impulso y eso no se ha hecho así (artículo 1 y 7 a 10 de la Ley de Gobierno). Es un simple acto político ajeno a cualquier proceso de elaboración de normas administrativas y sin cobertura presupuestaria que nos vuelve a colocar en medio de ese frondoso bosque donde la indefinición de conceptos, la indeterminación de fuentes y la confusión de rangos jurídicos nos impide ver algún árbol con claridad.

El gran problema que genera este "derecho blando" radica precisamente en el ámbito de las fuentes, situadas extramuros de la capacidad y competencia del legislador parlamentario e incluso al margen de los procedimientos de elaboración de las normas reglamentarias. En este caso, la aprobación de este Programa se constituiría en un "acto debido" que el Gobierno tiene la obligación de cumplimentar (Calvo Charro, 1995) y de hacerlo, además, previo conocimiento del Consejo para el Fomento de la Economía Social (actual artículo 13.5 de la LES), órgano al que también corresponde su seguimiento y evaluación según el propio Programa establece. Todo ello sencillamente se ha incumplido. Se trata de un serio problema de control de los procesos de aprobación de las normas y decisiones administrativas, de las dificultades casi insalvables de su acceso a la judicialización o de su posición en el conjunto del ordenamiento jurídico. En definitiva, un serio problema de indeterminación e inseguridad jurídica (Iglesias Vila, 2006).

\section{Conclusiones}

No cabe duda de que la aprobación y entrada en vigor de la Ley 5/2011 de ES ha supuesto un avance mayúsculo en lo que supone el reconocimiento institucional de la ES. Además, el establecimiento de los criterios básicos que identifican los rasgos esenciales de este sector, ya a nivel de Ley formal, aporta una muy necesaria seguridad jurídica, tan reiteradamente reclamada. El problema se concentra, por tanto, no especialmente en el texto de la norma que pudiera considerarse mejorable, sino en algo más dañino: su permanente estado de inocuidad.

Como señalábamos al inicio, la actual legislación relativa a entidades de la ES carece de los suficientes elementos comunes que permitan definir una teoría jurídica propia para la ES. La LES, a pesar de atribuirse la instauración de "un marco jurídico común para el conjunto de entidades que integran la economía social", no ha servido a tal propósito. La producción legislativa posterior a esta Ley apenas hace referencia a tal "marco común" o a su importancia o relevancia. Tal situación se ve agravada por la escasa aplicación efectiva de la LES, su nulo desarrollo reglamentario y su reciente reforma.

La LES ha permanecido durante más de cuatro años sin ser aplicada. Es a partir de 2015 cuando en cierta medida se ejecutan algunos de sus mandatos. Pero lo cierto es que algunas relevantes cuestiones siguen "congeladas" o, como el tema 
de la actividad del Consejo para el Fomento de la Economía Social, directamente incumplidas.

Ningún desarrollo reglamentario se ha llevado a cabo a pesar de los mandatos de la LES en tal sentido. Estamos ante una Ley de mínimos que precisaría de algún soporte reglamentario para conseguir una cierta eficacia. Pero ni tan siquiera lo más necesario ha sido abordado.

En el año 2015 la LES es reformada. Tal reforma incorpora algunas medidas más propias de decretos que de una Ley. Son medidas coyunturales, ligadas a las concretas situaciones de crisis económica, desempleo, cotizaciones, etc... Además, la reforma introduce un lamentable alarde de confusión de rangos legales que, a la larga, pueden propiciar un incontrolado proceso de deslegalización de la propia LES, sobre todo teniendo en cuenta la anulación, por vía de hecho, de la capacidad de intervención del Consejo para el Fomento de la Economía Social. Esta reforma induce a la indeterminación y garantiza la inseguridad jurídica, lo que reduce, y esto es lo verdaderamente importante, la efectividad de la LES y su consideración como norma jurídica.

Es cierto que este modo de legislar se está produciendo de manera frecuente en muchos otros ámbitos y que no es una característica propia de la ES, pero la ES precisa de instrumentos normativos más determinantes. Esta Ley 5/2011 es fruto de un proceso previo de varios años tanto en el área del trabajo científico como en el desarrollado por la Subcomisión para el fomento de la economía social, constituida en el seno de la Comisión de Economía y Hacienda del Congreso de los Diputados, de 26 de mayo de 2011 (Boletín Oficial de las Cortes Generales. Congreso de los Diputados de 2 de junio de 2011; n ${ }^{\circ} 581$ ) y también del Informe para la elaboración de una Ley de Fomento de la Economía Social realizada por varios expertos a petición del Ministerio de Trabajo e Inmigración (2010). Por ello, el resultado de estos precedentes no puede concluir en unos defectos de aplicación, desarrollo y reforma como los que hemos constatado.

El análisis efectuado sobre la aplicación, desarrollo y reforma de la LES, así como sobre su estructura y contenido nos acerca a la conclusión de que es una Ley con grandes defectos que la sitúan cerca de los conceptos de "derecho blando" y de "norma imperfecta", lo que no resulta apropiado a las necesidades y relevancia de un sector como el que representa la ES.

\section{Referencias bibliográficas}

Alarcon, G. (2010) El soft law y nuestro sistema de fuentes. Libro homenaje del profesor Álvaro Rodríguez Bereijo.

Alexy, R. (2001) Teoría de los derechos fundamentales. CEPC, Madrid.

Atienza, M. (1989) Contribución a una teoría de la legislación. Doxa. Cuadernos de filosofía del derecho, $\mathrm{N}^{\mathrm{o}} 6$, pp. 385-404.

Atienza, M. y Ruíz, J. (1996) Las piezas del Derecho. Teoría de los enunciados jurídicos. Barcelona.

Bentancourt, F. (2007) Derecho Romano Clásico. $3^{\text {a }}$ Edición. Editorial de la Universidad de Sevilla. 
Barreiro, G. y Estañ, M. C. (2004) La nueva regulación legal del régimen especial de Trabajadores Autónomos. Consejo General de Colegios Oficiales de Graduados Sociales de España.

Bonachela, M. (2011) Los preámbulos de los Estatutos de Autonomía entre la técnica legislativa y su trascendencia constitucional. Revista Teoría y Realidad Constitucional, No 27 , pp. 377-422.

Calvo, R. y Calvo, J. (2016) Las políticas sociales de la transición. Ediciones CincaColección Estudios. Serie fiscal. Madrid.

Calvo, M. (1995) Naturaleza jurídica del ejercicio de la potestad reglamentaria y consecuencias de la pasividad administrativa. Revista de Administración Pública, ${ }^{\circ}$ 137, pp. 239- 272.

Cano, A. (2002) Teoría jurídica de la Economía Social. La sociedad laboral: una forma jurídica de empresa de Economía Social. Consejo Económico y Social. Madrid.

Cano, A. (2007) El Derecho de la Economía Social: entre la Constitución y el mercado, la equidad y la eficiencia. Ciriec-España. Revista Jurídica de Economía Social y Cooperativa, $\mathrm{N}^{\mathrm{o}} 18$, pp. 53-72.

Cano, A. (2011) Entorno al concepto y caracterización jurídica de la empresa (rectius: sociedad) de inserción. Ciriec-España. Revista Jurídica de Economía Social y Cooperativa, $\mathrm{N}^{\mathrm{o}} 22$, pp. 43-74.

Del Toro, M. (2006) El fenómeno del soft law y las nuevas perspectivas del derecho internacional. Anuario Mexicano de Derecho Internacional, pp. 513-549.

Díez, L. M. (1992) Los preámbulos de las leyes (entorno a la motivación y la causa de las disposiciones normativas). Anuario de Derecho Civil, XLV, II, pp. 503-533.

Ezquiaga, F. J. (1988) Concepto, valor normativo y función interpretativa de las Exposiciones de Motivos y Preámbulos. Revista Vasca de Administración Pública, N ${ }^{\circ}$ 20.

Fajardo, G. (2009) La Economía Social en las leyes. Ciriec-España. Revista de Economía Pública, Social y Cooperativa, No 66, pp. 5-35.

Fajardo, G. (2012) Las empresas de la economía social en la Ley 5/2011, de 29 de marzo. Revista de Derecho de Sociedades (R.D.S.), No 38, pp. 245-280.

Fajardo, G. (2012) El fomento de la Economía Social en la legislación española. REVESCO. Revista de Estudios Cooperativos, No 107, pp. 58-97. DOI: 10.5209/rev_REVE.2012.v107.38747.

Gadea, E.; Sacristan, F. y Vargas, C. (2009) Régimen jurídico de la sociedad cooperativa del siglo XXI. Dykinson, SL.

García, E. y Fernández, T. R. (1995) Curso de Derecho Administrativo I. CIVITAS. Madrid.

García, E. (1999) Justicia y seguridad jurídica en un mundo de leyes desbocadas. CIVITAS. Madrid.

García, E. (2016) El régimen societario de las sociedades laborales en la nueva Ley 44/2015, de 14 de octubre, de Sociedades Laborales y Participadas." REVESCO. Revista de Estudios Cooperativos. DOI: 10.5209/REVE.52991.

Iglesias, M. (2006) Las fuentes de indeterminación del Derecho: una aproximación filosófica. Cuadernos de Derecho Público, No 28, pp. 55-82.

Martín, M. (1986) Preámbulos y Disposiciones Directas. Grupo de Estudios de Técnicas Legislativas (GRETEL): La reforma de las leyes. 10 estudios de técnica legislativa. BOSCH. Barcelona. 
Monzón, J. L. (2006) La Economía Social y conceptos afines: fronteras borrosas y ambigüedades conceptuales del Tercer Sector. Ciriec-España. Revista de Economía Pública, Social y Cooperativa, No 56, pp. 9-24.

Monzón, J. L. (coord.) (2010) Informe para la elaboración de una Ley de Fomento de la Economía Social. Ministerio de Trabajo y Asuntos Sociales. Madrid.

Muñoz, S. (1975) Sobre el concepto de Reglamento ejecutivo en el Derecho español. Revista de Administración Pública, № 77, pp. 139-180.

Olavarría, J. (2015) Las sociedades participadas: ¿un avance o un peligro?. Empresas gestionadas por sus trabajadores. Problemática jurídica y social. (coord. Fajardo, G.). Ciriec-España, pp.219-224.

Ollero, A. (2003) Estado Social y Democrático de Derecho. Algo más que retórica. El Modelo Social en la Constitución de 1978. AAVV. Ministerio de Trabajo y Asuntos Sociales. Madrid.

Paniagua, M. (2011) Las empresas de la economía social. Más allá del contenido de la Ley 5/2011, de economía social. Marcial Pons. Madrid.

Paniagua, M. (2013) Notas críticas a la Ley 14/2011, de 23 de diciembre, de Sociedades Cooperativas Andaluzas. Ciriec-España. Revista Jurídica de Economía Social y Cooperativa, $\mathrm{N}^{\mathrm{o}} 24$, pp. 53-115.

Paniagua, M. y Jiménez, J. (2014) La necesidad de una legislación cooperativa adecuada: aspectos mercantiles, tributarios y de Derecho comunitario. Ciriec-España. Revista de Economía Pública, Social y Cooperativa. № 81, pp. 61-93.

Parejo, L. (1992) Manual de Derecho Administrativo. AAVV. Ariel. Barcelona.

Paz, N. (2007) Errores legislativos sobre CTA y posibles remedios societarios". Revista Economía Social, No 39, pp. 19-23.

Paz, N. (2012) Comentario sistemático a la Ley 5/2011, de Economía Social. Tirant lo Blanch. Reformas. Valencia.

Pendas, B. (1989) Función de los parlamentos en materia de técnica legislativa. La calidad de las leyes. Parlamento Vasco. Colección informes y documentos, pp. 341-375. Vitoria-Gasteiz.

Pérez, J. M. (2012) Ley 5/2011, de 29 de marzo, de economía social ¿su aplicación es cosa de todos? (pregunta retórica). Revista Deusto Estudios Cooperativos, № 1, pp. 79-92 Bilbao.

Pérez, J. M. (2014) La inaplicación de la Ley de Economía Social en un contexto de crisis económica. Algunas interpretaciones y propuestas, Ciriec-España. Revista de Economía Pública, Social y Cooperativa, № 81, pp. 33-59.

Sánchez, L. A. (2008) Marco jurídico de las empresas de economía social. Dificultades y alternativas en la configuración de un estatuto jurídico para las entidades de la economía social. Ciriec-España. Revista Jurídica de Economía Social y Cooperativa, № 19, pp. 9-38.

Sánchez, L. A. (2009) La delimitación de las entidades y organismos de la economía social en la próxima ley reguladora del sector. Ciriec-España. Revista Jurídica de Economía Social y Cooperativa, $\mathrm{N}^{\mathrm{o}}$ 66, pp. 61-84.

Santamaría, J. A. (2004) Principios de Derecho Administrativo General I. Primera Edición. IUSTEL. Madrid.

Sarmiento, D. (2006) La autoridad del Derecho y la naturaleza del soft law. Cuadernos de Derecho Público, № 28, pp. 221-266.

Senent, M. J. y Fajardo, G. (2006) Aspectos relevantes de la investigación jurídica en Economía Social. Ciriec-España. Revista de Economía Pública, Social y Cooperativa, No 56 , pp. 187-223. 
Tajadura, J. (2000) Sobre los preámbulos de las leyes. Revista Jurídica de Navarra, No 29. Vicent, F. (1987) Perspectiva jurídica de la economía social en España. Ciriec-España. Revista de Economía Pública, Social y Cooperativa, No 2, pp. 15-44. 